\title{
Use of an intraventricular strip electrode for mesial temporal monitoring in children with medically intractable epilepsy
}

\author{
Hyunmi Kim, MD, PhD, MPH, ${ }^{1,2}$ Ahyuda Oh, DDS, MBA, DrPH, ${ }^{1}$ Larry Olson, MD, ${ }^{1,2}$ and \\ Joshua J. Chern, MD, PhD 3,4 \\ Departments of ${ }^{1}$ Pediatrics and ${ }^{3}$ Neurosurgery, Emory University School of Medicine; and ${ }^{2 D i v i s i o n ~ o f ~ P e d i a t r i c ~ N e u r o l o g y ~ a n d ~}$ \\ ${ }^{4}$ Pediatric Neurosurgery Associates, Children's Healthcare of Atlanta, Georgia
}

\begin{abstract}
OBJECTIVE The objective of this study was to evaluate mesial temporal electroencephalographic (EEG) monitoring, using an intraventricular strip electrode (IVSE) along the ventricular surface of the hippocampus, in children with medically intractable epilepsy.

METHODS The authors reviewed 10 consecutive cases in which subdural electrode placements and mesial temporal monitoring were recommended. The median age of the patients was 12.7 years (range 4.5-19.3 years). Both grids and IVSE were placed in all patients. The 4-contact IVSE was used in 5 cases, and the 6 -contact IVSE in the other 5 cases. The median number of contacts, including IVSE contacts, was 122 (range 66-181). A total of 182 seizures were analyzed.
\end{abstract}

RESULTS The IVSE localized seizure-onset zones in 8 patients. The seizure-onset zone was identified exclusively by IVSE in 3 patients and was simultaneous in IVSE and subdural electrodes in 5 patients. Among the 5 patients with simultaneous onset on both IVSE and subdural electrodes, 4 had basal temporal onset and one had orbitofrontal and lateral midtemporal onset. In the remaining 2 patients, the absence of IVSE seizure onset permitted sparing of mesial temporal structures. An Engel Class la outcome was achieved in 9 of 10 cases. No complication was associated with IVSE placement.

CONCLUSIONS Intracranial monitoring using IVSE offers an alternative in terms of quality of EEG recording. IVSE was useful in children who already required open craniotomy for intracranial monitoring over an extensive network of hyperexcitability.

https://thejns.org/doi/abs/10.3171/2016.10.PEDS16407

KEY WORDS children; epilepsy surgery; intraventricular strip electrode; mesial temporal monitoring

I NTRACRANIAL electroencephalographic (EEG) recordings are used to identify seizure onset zones for resective epilepsy surgery in patients with medically intractable epilepsy. The hypothesis of the localization of seizure-onset zones is constructed based on seizure semiology and interpretations of multimodal presurgical workups, such as long-term video-EEG monitoring and structural and functional imaging studies. ${ }^{11,16,17}$ In temporal lobe epilepsy, seizure onset can originate from mesial structures, neocortex, or both. To make a decision whether hippocampal removal is necessary or not, mesial temporal monitoring is frequently required.
Traditionally, depth electrodes are used to study the mesial temporal lobe and other limbic structures.5,24-26 Depth electrodes can be inserted through the medial occipital lobe into the long axis of the hippocampus and reach the amygdala ${ }^{5,19,25}$ or can be inserted orthogonally to the long axis of the hippocampus through the middle temporal gyrus.,15 A less frequently employed approach is to place electrodes intraventricularly over the hippocampus. The temporal horn of the lateral ventricle can be entered from the occiput or the temporal lobe, with the aid of stereotaxy or endoscopy. ${ }^{3,14,20}$ Depth electrode placement with stereotactic technique has some limitations. 1) The

ABBREVIATIONS CHOA = Children's Healthcare of Atlanta; EEG = electroencephalographic; FDG-PET = fluorodeoxyglucose positron emission tomography; ISAS = ictalinterictal SPECT analyzed by statistical parametric mapping; IVSE = intraventricular strip electrode; MTS = mesial temporal sclerosis; SISCOM = subtraction ictal SPECT co-registered to MRI; SPECT = single photon emission computed tomography.

SUBMITTED July 13, 2016. ACCEPTED October 26, 2016.

INCLUDE WHEN CITING Published online February 3, 2017; DOI: 10.3171/2016.10.PEDS16407. 
targeting is not always accurate because of the complex morphology of the mesial temporal lobe, the depth, and the relative position of the ventricular spaces. 2) Multiple depth electrodes are needed if one is to sample the entire length of the hippocampus from a lateral approach. Although the rate of morbidity related to depth electrode placement is low, intracranial hemorrhage has been a concern, especially in the dominant hemisphere. ${ }^{21}$

As an alternative to depth electrodes, subdural strip electrodes have also been used for mesial temporal recordings. Typically, 2 or 3 strips have been applied subtemporally and perpendicular to the long axis of the temporal lobe to monitor the amygdala and hippocampal head, body, and tail. The suboptimal placement of subtemporal subdural electrodes has been reported, ${ }^{8}$ and the posterior subtemporal strip may damage the bridging vein. ${ }^{7}$ Less commonly, a subdural strip has been placed by an anteromedial approach along the temporal pole and the medial basal temporal lobe surface, which allows recording from the parahippocampal gyrus along its long axis.? However, the subdural strip electrodes were reported to be less sensitive than hippocampal depth electrodes because subdural strip electrodes detect the later spreading activity while depth electrodes record the beginning of seizures in the hippocampus. ${ }^{8,24,26}$ The difference in the quality of recording of depth and subdural strip electrodes is more likely to arise from their distance to hippocampal structures.

The technique of intraventricular strip electrode (IVSE) monitoring was first described by Polkey et al. ${ }^{20}$ and involves placement of a strip electrode over the ventricular surface of the hippocampus for direct recording.

In this study, we report our experience using this technique in the pediatric population. The surgical technique is described and electrophysiological and clinical data are presented.

\section{Methods}

\section{Surgical Pathway of Children With Medically Intractable Temporal Lobe Epilepsy}

Patients with medically intractable temporal lobe epilepsy patients undergo a comprehensive presurgical evaluation, including diagnostic video-EEG (interictal and ictal) monitoring, brain MRI with epilepsy surgery protocol, fluorodeoxyglucose positron emission tomography (FDG-PET), and neuropsychological assessments including nonverbal and verbal memory and frontal lobe function testing. Functional MRI is considered if the suspected seizure-onset zone is close to a potentially eloquent functional area. Single photon emission computed tomography (SPECT) with subtraction ictal SPECT co-registered to MRI (SISCOM) or ictal-interictal SPECT analyzed by statistical parametric mapping (ISAS) are conducted when there are discordant findings among the baseline tests. Wada testing may be performed when there are concerns about potential decline in verbal memory as a complication of surgery.

The results of the aforementioned studies are then reviewed by our multidisciplinary team consisting of epileptologists, neuroradiologists, neuropsychologists, and neu- rosurgeons. Invasive monitoring is proposed on the basis of consensus. Intracranial monitoring with combined subdural strip/grid electrodes and/or depth electrodes is used to localize the seizure-onset zone and to define the resection margin for the epilepsy surgery. Grid maps are generated using CURRY SCAN 7 co-registration software (Compumedics) by incorporating preoperative MRI and postimplantation high-resolution CT scans. The multimodal imaging co-registration provides the grid localization with 3D information (Fig. 1). For accurate anatomical mapping of both epileptogenic tissue and eloquent cortex, the location of each individual electrode must be established with reasonable accuracy. ${ }^{16}$

\section{Patients}

This study involved 10 consecutive patients (6 males and 4 females) who underwent subdural electrode placement and mesial temporal monitoring at Children's Healthcare of Atlanta (CHOA) between August 2013 and July 2015. The patients' median age at surgery was 12.7 years (4.5-19.3 years). Eight patients were right-handed, one was left-handed, and in another handedness was indeterminate. Each patient underwent the following presurgical evaluation: interictal/ictal video-EEG monitoring, brain MRI, FDG-PET brain scan, and neuropsychological tests. Ictal SPECT was performed in 6 cases. All 10 patients had visible lesions on brain MRI (Table 1). Intracranial monitoring was recommended to explore the complexity of epileptogenic networks. In Cases 2, 3, 4, 5, 6,8 , and 9 , seizure semiology and EEG findings suggested neocortical involvement. The patients in Cases 5, 7, and 9 had lesions with multilobar involvement on brain MRI. The patients in Cases 1 and 4 were undergoing repeat surgery, and precise decisions were required regarding the resection margins. Accordingly, both grids and IVSEs were placed in all patients. The median number of contacts, including IVSE contacts, was 122 (range 66-181).

The study was approved by the institutional review board of CHOA and was performed in compliance with the Health Insurance Privacy and Portability Act.

\section{Surgical Technique: Ventricular Placement of Electrodes Over the Hippocampus}

Either 4- or 6-contact strip electrodes (Integra LifeSciences Corp.) were used in all cases. Contacts were spaced $10 \mathrm{~mm}$ apart. One strip electrode was placed per patient. The 4-contact electrodes were applied in 5 cases, and the 6-contact electrodes in the other 5 cases.

The craniotomies were tailored to expose temporal and/or frontal and/or parietal areas. Without removal of the lateral orbital rim or posterior-inferior reflection of the temporalis muscle, the anterior-most exposure of the temporal lobe is typically within $4 \mathrm{~cm}$ of the temporal tip. At a minimum, the sylvian fissure and the superior and middle temporal gyri were exposed. With ultrasound or frameless stereotaxy guidance, a 1-cm corticectomy was made at the anterior middle temporal gyrus, and dissection was carried through the white matter until the temporal horn of the lateral ventricle was reached. The curved end of a No. 3 Penfield dissector was then used to guide 

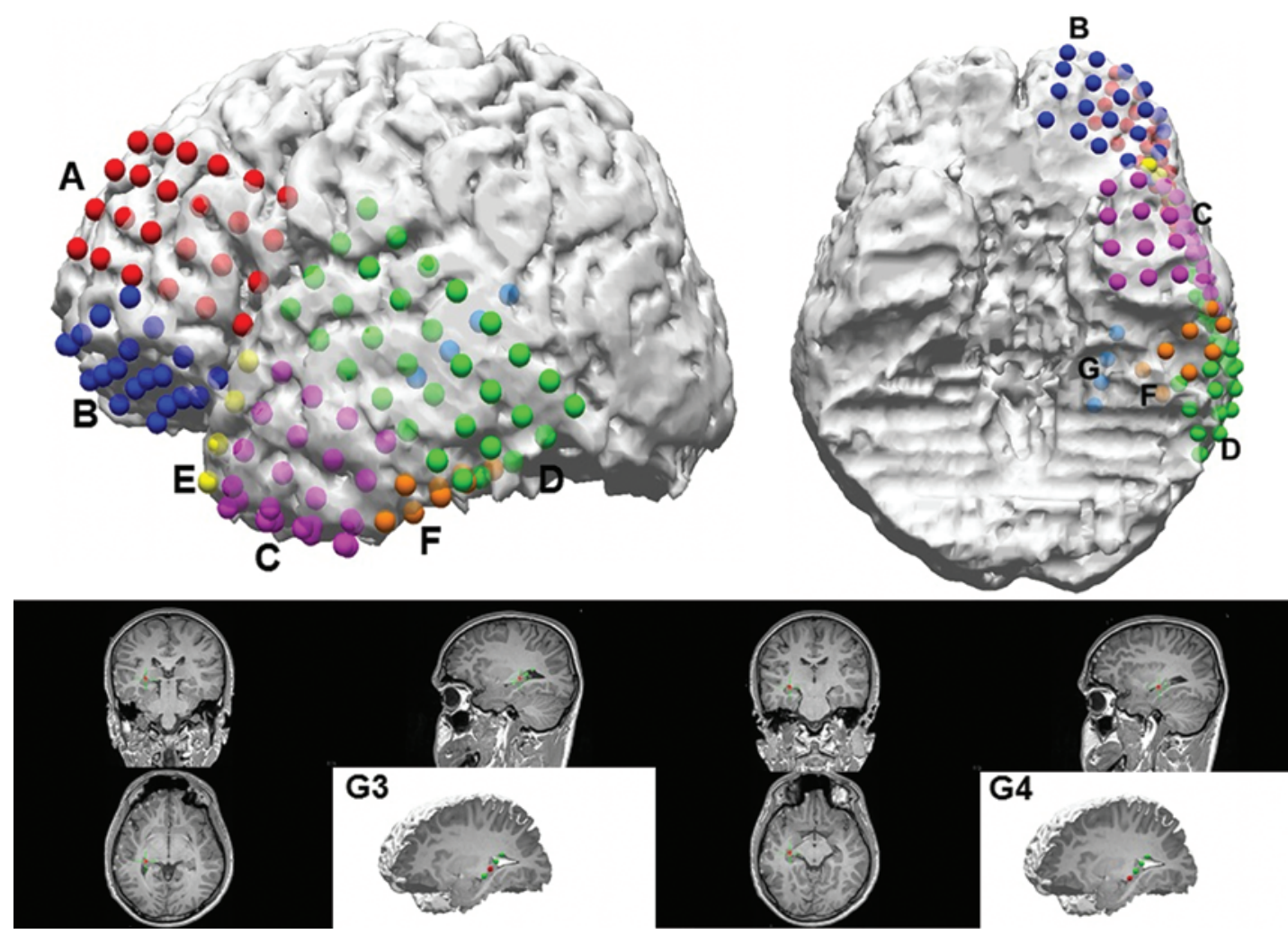

FIG. 1. Case 6. 3D strip electrode maps created using co-registration software (CURRY SCAN 7) by incorporating data from preoperative T1-weighted MRI and postimplantation high-resolution CT. The red dots provide a 3D depiction of the strip electrode contacts in the left temporal ventricle, showing the coverage over the temporal region. Figure is available in color online only.

the insertion of the strip electrode (Fig. 2) and its placement along the long axis of the hippocampus. No resistance was encountered when the electrode was advancing properly along the ventricle surface. When resistance was encountered, the electrode was often over the hippocampal head and advancing toward the uncus (medially) and not toward the hippocampal body (posteriorly). Once the electrode was placed intraventricularly, the tail of the electrode was anchored to the dura and the scalp to prevent migration.

\section{Results}

Table 2 shows seizure outcomes and the intracranial monitoring data, including the number of electrodes placed and seizures recorded. The median number of contacts, including IVSE contacts, used per case was 122 (range 66-181). Both grids and IVSE were placed in all patients. No intraventricular hemorrhage was observed on immediate postoperative imaging. A total of 182 seizures were analyzed. In 2 patients, only subclinical seizures were recorded.

The IVSE captured the seizure-onset zone in 8 patients (Table 2). Figure 3 depicts a seizure-onset pattern on electroencephalogram. Seizure-onset zone was localized exclusively by IVSE in 3 patients (Cases 1,2, and 7) and was simultaneous in IVSE and subdural electrodes in 5 patients (Cases 3, 4, 6, 8, and 10). Among the 5 patients with simultaneous onset on both IVSE and subdural electrodes,
4 had basal temporal onset and 1 had orbitofrontal and lateral midtemporal onset (Case 6). Accordingly, a temporal lobectomy was performed in the 8 patients in whom the seizure-onset zone was identified. The 2 patients (Cases 5 and 9) whose seizures were not identified by IVSE underwent resective surgery with sparing of the hippocampus and the parahippocampal gyrus.

Nine patients became seizure free (Engel Class I) ${ }^{9}$ after surgery (median duration of follow-up 18 months, range 6-33 months). The remaining patient had worthwhile seizure reduction postoperatively (Engel Class IIIa). In 8 patients, no newly developed neurological deficits occurred as a result of the resective surgery. Two of the 10 patients experienced surgery-related complications. One patient (Case 4) had a left middle cerebral artery stroke after temporal and orbitofrontal resections, which resulted in moderate right hemiparesis and transient aphasia. The other patient (Case 5) had signs of intracranial pressure elevation during intracranial monitoring, possibly due to the high number of intracranial electrodes placed (181), and the electrodes were promptly removed. Resective surgery in this patient was based on the interictal findings and 1 ictal recording. The patient experienced transient right hemiparesis and aphasia but eventually recovered fully and remains free from habitual seizures, having had only a single episode of aura in the immediate postoperative period. These 2 complications, one related to temporal lobectomy and one related to the hardware burden 
TABLE 1. Findings from multimodal presurgical evaluation

\begin{tabular}{|c|c|c|c|c|c|c|c|c|}
\hline \multirow[b]{2}{*}{$\begin{array}{l}\text { Case } \\
\text { No. }^{*}\end{array}$} & \multicolumn{2}{|c|}{ Pt Age (yrs) } & \multirow[b]{2}{*}{ Sz Semiology } & \multicolumn{2}{|c|}{ Scalp EEG Results } & \multicolumn{3}{|c|}{ Imaging Abnormalities } \\
\hline & $\begin{array}{l}\text { At Sz } \\
\text { Onset }\end{array}$ & $\begin{array}{l}\text { At } \\
\text { Op }\end{array}$ & & Interictal† & Ictalf & MRI & $\begin{array}{l}\text { FDG- } \\
\text { PET }\end{array}$ & $\begin{array}{l}\text { SPECT } \\
\text { (SISCOM/ } \\
\text { ISAS) }\end{array}$ \\
\hline 1 & 11.2 & 14.6 & $\begin{array}{l}\text { Aura (strange feeling in chest \& abdo- } \\
\text { men), saying words/sentences out } \\
\text { of context, excessive drooling }\end{array}$ & Rt T & Rt T & $\begin{array}{l}\text { s/p rt T resection; rt T } \\
\text { residual tumor }\end{array}$ & $\begin{array}{l}\text { Rt mT; l; } \\
\quad \text { OF }\end{array}$ & Not done \\
\hline 2 & 13.0 & 19.3 & $\begin{array}{l}\text { Behavioral arrest, tonic posturing of It } \\
\text { face \& arm, GTCS }\end{array}$ & Rt T & Lateralized to rt & $\begin{array}{l}\text { Rt MTS; encephalomalacia } \\
\text { in It prefrontal region }\end{array}$ & Rt T; Lt F & Rt T \\
\hline $3 \S$ & 0.0 & 5.4 & 1) spasms; 2) tonic Sz & Bilat TO & Nonlateralized & Rt T mass & Rt mT, T & Rt OF, T \\
\hline 4 & 6.0 & 10.8 & $\begin{array}{l}\text { Aura (buzzing in head or blurry vi- } \\
\text { sion), staring, opening mouth }\end{array}$ & Lt T & Lt T & $\mathrm{s} / \mathrm{p}$ It selective $\mathrm{AH}$ & Lt T & Lt T \\
\hline 5 & 12.8 & 15.2 & $\begin{array}{l}\text { 1) head version to right, tonic Sz; } \\
\text { 2) staring, purposeless movements }\end{array}$ & None & Lt T & Lt H nonspecific vol loss & Lt T & Lt F, T \\
\hline 6 & 15.0 & 16.0 & $\begin{array}{l}\text { Nonspecific aura, agitation, chewing, } \\
\text { GTCS }\end{array}$ & Lt T; bilat F; G & $\begin{array}{r}\text { Sz not re- } \\
\text { corded }\end{array}$ & Lt T mass & Lt T & Not done \\
\hline 7 & 1.7 & 10.2 & $\begin{array}{l}\text { Restlessness, looking around, fidget- } \\
\text { ing w/ both hands, chewing, GTCS }\end{array}$ & Lt T & Lateralized to It & $\begin{array}{l}\text { Lt MTS; It ant T \& diffuse } \\
\text { cerebral atrophy }\end{array}$ & Lt T & Not done \\
\hline 8 & 0.3 & 4.5 & Spasms & Bilat T; bilat F; G & Nonlateralized & Rt T mass & Rt T & Rt F, T \\
\hline $9 \pi$ & 10.0 & 10.1 & $\begin{array}{l}\text { Brief body jerk, rt arm tonic extension, } \\
\text { head/body version to rt }\end{array}$ & Bilat T; bilat F; G & Lateralized to It & Lt PO encephalomalacia & Lt P, T, O & Not done \\
\hline 10 & 12.0 & 15.1 & Staring & Lt F, T & Lt F, T & Lt T encephalocele & Lt T & Lt T \\
\hline
\end{tabular}

$\mathrm{AH}=$ amygdalohippocampectomy; ant = anterior; $\mathrm{F}=$ frontal; $\mathrm{G}=$ generalized; $\mathrm{GTCS}=$ generalized tonic-clonic seizure; $\mathrm{H}=$ hemispheric; $\mathrm{I}=$ insular; $\mathrm{mT}=$ mesial temporal; $\mathrm{O}=$ occipital; $\mathrm{OF}=$ orbito-frontal; $\mathrm{P}=$ parietal; $\mathrm{PO}=$ parieto-occipital; $\mathrm{Pt}=$ patient; $\mathrm{s} / \mathrm{p}=$ status post; $\mathrm{Sz}=$ seizure; $\mathrm{T}=$ temporal; $\mathrm{TO}=$ temporo-occipital.

* Patients were right handed unless otherwise indicated.

$\dagger$ Epileptiform abnormality.

$\ddagger$ Seizure-onset zone.

$\S$ Handedness undetermined.

II Left handed.
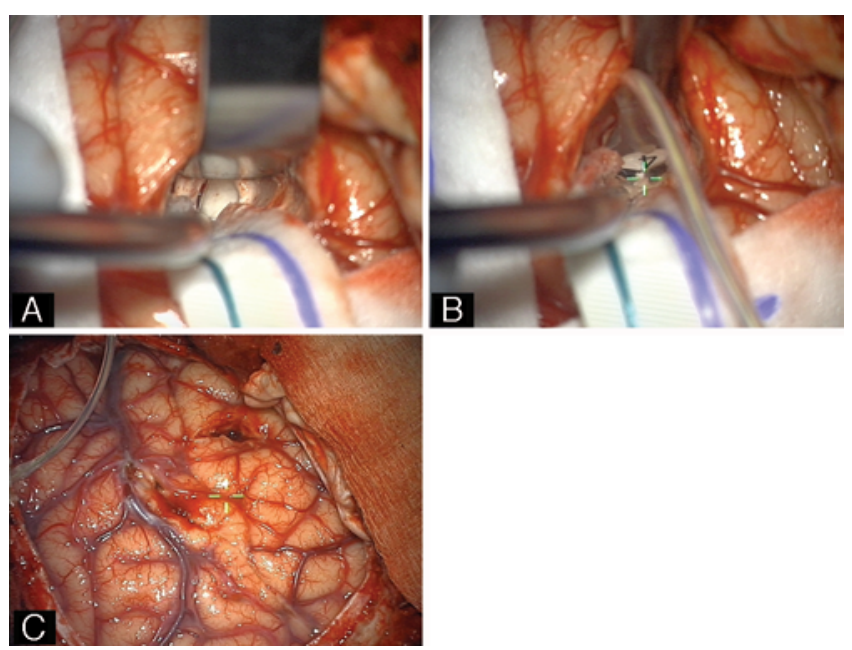

FIG. 2. Intraoperative photographs. A: Image obtained before IVSE insertion. The temporal horn was approached transcortically with minimal corticectomy. B: Image showing insertion of the strip electrode with the guidance of a No. 3 Penfield dissector. C: Image obtained at the time of resection, after removal of the strip electrode, allowing appreciation of the size of the corticectomy. In all photographs, anterior is up. Figure is available in color online only. incurred by invasive monitoring, are similar to complications that have been documented in the neurosurgical literature. ${ }^{10,18,22}$ They represented the 2 most severe complications that we had experienced in our institution in the last 5 years. However, neither of these complications was associated with IVSE placement. In postoperative imaging obtained immediately after the surgery, no intraventricular hemorrhage was observed.

Pathological findings showed that mesial temporal sclerosis (MTS) was most frequently found $(n=5)$, followed by tumors $(n=4)$. Dual pathology was appreciated in 4 cases (sickle cell anemia-associated multiple strokes, ganglioglioma, focal cortical dysplasia IIIa, ${ }^{2}$ and focal encephalocele). Brain MRI did not show the evidence of MTS in 3 of 4 cases of pathologically confirmed MTS. Focal cortical dysplasia was revealed on MRI in 2 cases. In 1 case, left MTS was found in the setting of left temporal and diffuse cerebral atrophy. In 1 case, remote postischemic encephalomalacia was identified.

\section{Discussion}

This study documents our experience with invasive recording of mesial temporal structures using a strip electrode in the temporal horn of lateral ventricle. Seizure onset was detected and localized to the mesial temporal lobe by IVSE in 8 of 10 patients. In the remaining 2 patients, 
TABLE 2. Summary of intracranial monitoring and surgical outcomes

\begin{tabular}{|c|c|c|c|c|c|c|c|c|}
\hline \multirow{2}{*}{$\begin{array}{l}\text { Case } \\
\text { No. }\end{array}$} & \multicolumn{3}{|c|}{ No. of Contacts } & \multirow{2}{*}{$\begin{array}{c}\text { No. of SzS } \\
\text { Captured by IVSE* }\end{array}$} & \multirow[b]{2}{*}{ Resection } & \multirow[b]{2}{*}{ Pathology } & \multirow{2}{*}{$\begin{array}{l}\text { Follow-Up } \\
\text { (mos) }\end{array}$} & \multirow{2}{*}{$\begin{array}{l}\text { Engel } \\
\text { Class }\end{array}$} \\
\hline & Grid & Surface Strip, IVSE & Depth & & & & & \\
\hline 1 & 76 & 0,4 & 4 & $7 / 7$ & Rt mT, OF & Neurocytoma & 33 & la \\
\hline 2 & 48 & 6,6 & 6 & $24 / 24 \dagger$ & Rt T & SCA-associated multiple strokes; MTS & 24 & la \\
\hline 3 & 127 & 0,6 & 0 & $30 / 83$ & Rt T‡ & Oligodendroglioma (WHO Gr II) & 24 & la \\
\hline 4 & 107 & 14,6 & 0 & $8 / 8$ & Lt T‡ & Ganglioglioma (WHO Gr I); FCD & 29 & la \\
\hline 5 & 159 & 0,6 & 16 & $0 / 1$ & Lt $P, T$ & Not done & 25 & la \\
\hline 6 & 108 & 4,4 & 0 & $2 / 2$ & Lt T, OF $\ddagger$ & Ganglioglioma (WHO Gr I); MTS & 13 & la \\
\hline 7 & 75 & 4,4 & 32 & $3 / 3$ & Lt T & MTS & 13 & Illa \\
\hline 8 & 75 & 10,4 & 50 & $23 / 23$ & Rt T, OF $\ddagger$ & FCD ॥B, MTS & 9 & la \\
\hline 9 & 71 & 0,6 & 70 & $0 / 22 \dagger$ & Lt TO, P & Remote postischemic encephalomalacia & 6 & la \\
\hline 10 & 47 & 18,4 & 0 & $8 / 9$ & Lt T‡ & Encephalocele; MTS & 9 & la \\
\hline
\end{tabular}

$\mathrm{FCD}=$ focal cortical dysplasia; $\mathrm{Gr}$ = grade; IVSE = intraventricular strip electrode; $\mathrm{SCA}=$ sickle cell anemia.

* The denominators indicate the total number of recorded seizures, and the numerators present the number of seizures arising from sites of temporal ventricular strip electrodes.

† Only electrographic seizures were recorded.

$\ddagger$ Simultaneous onset in subdural contacts.

the absence of IVSE seizure-onset permitted sparing of mesial temporal structures. An Engel Class Ia outcome was achieved in 9 of 10 cases.

Dual pathology, in which MTS coexists with an extrahippocampal epileptogenic lesion, is found more frequently in children than adults. ${ }^{12}$ This possibility should be considered in children with neuronal migration disorders, low-grade tumors, vascular malformations, porencephalic cysts, and gliotic lesions as a result of cerebral insults early in life. ${ }^{6}$ In the current study, dual pathology was confirmed in 4 cases, and MTS was associated with strokes, ganglioglioma, focal cortical dysplasia IIIa, and focal encephalocele. Furthermore, in 3 of 4 patients with a tissue diagnosis of MTS, brain MRI did not show evidence of MTS. This finding supports that, even when not appreciated on brain MRI, the condition of dual pathology may be present and needs to be examined in children.

Because of the physical proximity and the susceptibility to seizure generation in the common network of hyperexcitability, mesial temporal structures are frequently

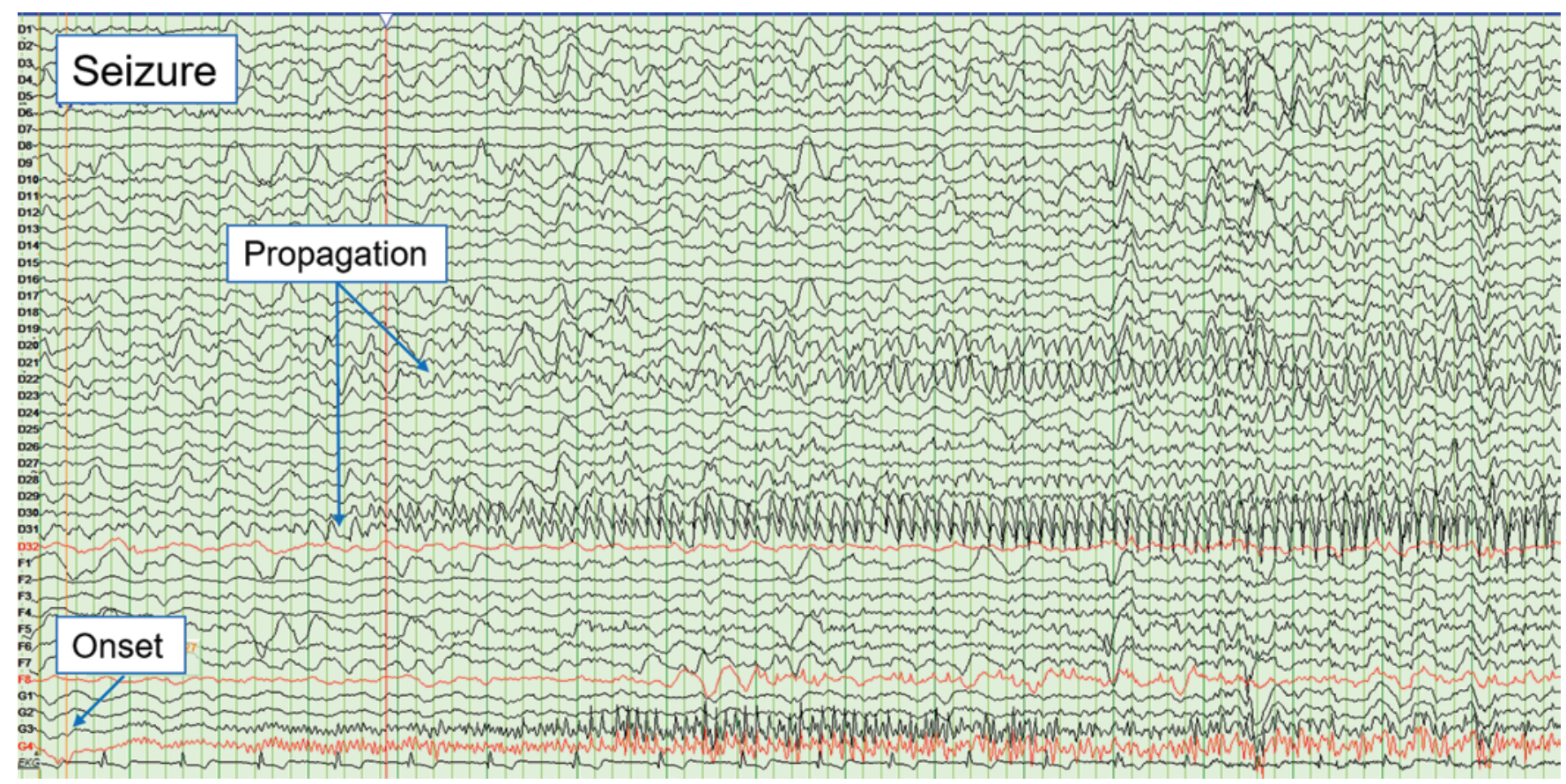

FIG. 3. Case 6. EEG recording of seizure onset from the IVSE in the left temporal horn of the lateral ventricle, labeled G1-G4. Sensitivity $70 \mu \mathrm{V} / \mathrm{mm}$, low-frequency filter $1 \mathrm{~Hz}$, high-frequency filter $70 \mathrm{~Hz}$. EKG = electrocardiogram. Figure is available in color online only. 
investigated in patients with mesial temporal, neocortical temporal, or extratemporal epilepsy. When the mesial structure is confirmed to be involved in seizure onset based on electrophysiological data, removal is associated with improved seizure outcome..$^{4,13}$ However, the possibility of verbal memory loss needs to be considered, particularly in the settings of dominant hemisphere involvement, absence of unilateral MTS on imaging, or intact preoperative verbal memory function. ${ }^{27}$ Mesial temporal monitoring was necessary in our cases to evaluate whether the hippocampus could be spared or not. Combined subdural strip/grid electrodes and/or depth electrodes allow recording from both superficial and deep cortex, and are helpful for identifying seizure-onset zones. ${ }^{11,21,24}$ Depth electrodes have been used primarily to monitor the medial temporal structures ${ }^{5,24-26}$ because subdural strip electrodes were known to be less sensitive. Subdural strip electrodes detect the later spreading activity, whereas depth electrodes record the beginning of seizures in the hippocampus. ${ }^{8,24,26}$ However, depth electrode placement with stereotactic technique has limitations, such as target failure or inability to sample across the whole length of the hippocampus with the midtemporal approach. ${ }^{21}$

Various techniques have been reported to directly record from the ventricular surface of the hippocampus. A multicontact electrode line has been stereotactically placed in the temporal horn of the lateral ventricle from an occipital approach to record from the mesial temporal region intraoperatively. ${ }^{3} \mathrm{~A}$ T-shaped electrode ${ }^{20}$ or a strip electrode $^{14}$ has been introduced into the temporal horn from a midtemporal approach to record from the mesial temporal structures intraoperatively. For long-term intracranial monitoring, Song et al. ${ }^{23}$ suggested an intraventricular depth electrode technique using stereotactic guidance and endoscope as an alternative to transcortical depth electrode placement and reported a thalamic contusion as a serious complication in 1 of 8 cases. However, this approach has not been widely used.

In our study, a strip with 4 or 6 contacts was safely placed into the temporal horn of the lateral ventricle from the anterior middle temporal gyrus to abut the amygdalohippocampal complex and extending posteriorly, which allowed successful recording of the whole length of the mesial temporal structure and facilitated decisions regarding the posterior resection margin of the hippocampus. There was no complication associated with IVSE placement in our 10 cases.

\section{Conclusions}

Intracranial monitoring using IVSE offers an alternative in terms of quality of EEG recording as well as safety and convenience of the technique at least comparable to that of traditional depth electrodes for monitoring mesial temporal structures. IVSE was useful in children who already required open craniotomy for intracranial monitoring over an extensive network of hyperexcitability.

\section{References}

1. Bartolomei F, Bettus G, Stam CJ, Guye M: Interictal network properties in mesial temporal lobe epilepsy: a graph theoreti- cal study from intracerebral recordings. Clin Neurophysiol 124:2345-2353, 2013

2. Blümcke I, Thom M, Aronica E, Armstrong DD, Vinters HV, Palmini A, et al: The clinicopathologic spectrum of focal cortical dysplasias: a consensus classification proposed by an ad hoc Task Force of the ILAE Diagnostic Methods Commission. Epilepsia 52:158-174, 2011

3. Blume WT, Parrent AG, Kaibara M: Stereotactic amygdalohippocampotomy and mesial temporal spikes. Epilepsia 38:930-936, 1997

4. Cascino GD, Jack CR Jr, Parisi JE, Sharbrough FW, Schreiber CP, Kelly PJ, et al: Operative strategy in patients with MRI-identified dual pathology and temporal lobe epilepsy. Epilepsy Res 14:175-182, 1993

5. Cascino GD, Trenerry MR, Sharbrough FW, So EL, Marsh WR, Strelow DC: Depth electrode studies in temporal lobe epilepsy: relation to quantitative magnetic resonance imaging and operative outcome. Epilepsia 36:230-235, 1995

6. Cendes F, Cook MJ, Watson C, Andermann F, Fish DR, Shorvon SD, et al: Frequency and characteristics of dual pathology in patients with lesional epilepsy. Neurology 45:2058-2064, 1995

7. Cohen-Gadol AA, Spencer DD: Use of an anteromedial subdural strip electrode in the evaluation of medial temporal lobe epilepsy. Technical note. J Neurosurg 99:921-923, 2003

8. Eisenschenk S, Gilmore RL, Cibula JE, Roper SN: Lateralization of temporal lobe foci: depth versus subdural electrodes. Clin Neurophysiol 112:836-844, 2001

9. Engel J Jr, Van Ness PC, Rasmussen T, Ojemann LM: Outcome with respect to epileptic seizures, in Engel J Jr (ed): Surgical Treatment of the Epilepsies, ed 2. New York: Raven Press, 1993, pp 609-621

10. Hamer HM, Morris HH, Mascha EJ, Karafa MT, Bingaman WE, Bej MD, et al: Complications of invasive video-EEG monitoring with subdural grid electrodes. Neurology 58:97103,2002

11. Kim H, Lee C, Knowlton R, Rozzelle C, Blount JP: Safety and utility of supplemental depth electrodes for localizing the ictal onset zone in pediatric neocortical epilepsy. J Neurosurg Pediatr 8:49-56, 2011

12. Lee YJ, Kang HC, Bae SJ, Kim HD, Kim JT, Lee BI, et al: Comparison of temporal lobectomies of children and adults with intractable temporal lobe epilepsy. Childs Nerv Syst 26:177-183, 2010

13. Li LM, Cendes F, Andermann F, Watson C, Fish DR, Cook MJ, et al: Surgical outcome in patients with epilepsy and dual pathology. Brain 122:799-805, 1999

14. McBride MC, Binnie CD, Janota I, Polkey CE: Predictive value of intraoperative electrocorticograms in resective epilepsy surgery. Ann Neurol 30:526-532, 1991

15. Memarian N, Madsen SK, Macey PM, Fried I, Engel J Jr, Thompson PM, et al: Ictal depth EEG and MRI structural evidence for two different epileptogenic networks in mesial temporal lobe epilepsy. PLoS One 10:e123588, 2015

16. Nair DR, Burgess R, McIntyre CC, Lüders H: Chronic subdural electrodes in the management of epilepsy. Clin Neurophysiol 119:11-28, 2008

17. Nair DR, Mohamed A, Burgess R, Lüders H: A critical review of the different conceptual hypotheses framing human focal epilepsy. Epileptic Disord 6:77-83, 2004

18. Onal C, Otsubo H, Araki T, Chitoku S, Ochi A, Weiss S, et al: Complications of invasive subdural grid monitoring in children with epilepsy. J Neurosurg 98:1017-1026, 2003

19. Park YD, Murro AM, King DW, Gallagher BB, Smith JR, Yaghmai F: The significance of ictal depth EEG patterns in patients with temporal lobe epilepsy. Electroencephalogr Clin Neurophysiol 99:412-415, 1996

20. Polkey CE, Binnie CD, Janota I: Acute hippocampal record- 
ing and pathology at temporal lobe resection and amygdalohippocampectomy for epilepsy. J Neurol Neurosurg Psychiatry 52:1050-1057, 1989

21. Ross DA, Brunberg JA, Drury I, Henry TR: Intracerebral depth electrode monitoring in partial epilepsy: the morbidity and efficacy of placement using magnetic resonance imageguided stereotactic surgery. Neurosurgery 39:327-334, 1996

22. Schmidt RF, Wu C, Lang MJ, Soni P, Williams KA Jr, Boorman DW, et al: Complications of subdural and depth electrodes in 269 patients undergoing 317 procedures for invasive monitoring in epilepsy. Epilepsia 57:1697-1708, 2016

23. Song JK, Abou-Khalil B, Konrad PE: Intraventricular monitoring for temporal lobe epilepsy: report on technique and initial results in eight patients. J Neurol Neurosurg Psychiatry 74:561-565, 2003

24. Spencer SS, Spencer DD, Williamson PD, Mattson R: Combined depth and subdural electrode investigation in uncontrolled epilepsy. Neurology 40:74-79, 1990

25. Spencer SS, Spencer DD, Williamson PD, Mattson RH: The localizing value of depth electroencephalography in 32 patients with refractory epilepsy. Ann Neurol 12:248-253, 1982

26. Sperling MR, O'Connor MJ: Comparison of depth and subdural electrodes in recording temporal lobe seizures. Neurology 39:1497-1504, 1989
27. Stroup E, Langfitt J, Berg M, McDermott M, Pilcher W, Como P: Predicting verbal memory decline following anterior temporal lobectomy (ATL). Neurology 60:1266-1273, 2003

\section{Disclosures}

The authors report no conflict of interest concerning the materials or methods used in this study or the findings specified in this paper.

\section{Author Contributions}

Conception and design: Kim, Chern. Acquisition of data: Kim, Oh. Analysis and interpretation of data: Kim, Oh. Drafting the article: Kim, Oh, Chern. Critically revising the article: all authors. Reviewed submitted version of manuscript: all authors. Approved the final version of the manuscript on behalf of all authors: Kim. Administrative/technical/material support: Kim, Chern.

\section{Correspondence}

Hyunmi Kim, Department of Pediatrics, Emory University School of Medicine, 1605 Chantilly Dr. NE, Ste. 300, Atlanta, GA 30324. email: hyunmi.kim@emory.edu. 